\title{
Sociodemographic and Health Predictors of Concern about COVID-19 Infection in Cuban Patients with Type 2 Diabetes Mellitus
}

\author{
Tomás Caycho-Rodríguez ${ }^{1 *}$ (), Pablo D Valencia ${ }^{2}$ (), Lindsey W Vilca ${ }^{3}$ (D), Ibraín Enrique Corrales-Reyes ${ }^{4}$ (D), \\ Frank Hernández-García ${ }^{5}$ (1), Antonio Pupo Pérez ${ }^{6}{ }^{(0)}$, Patricia González Quintana ${ }^{7}$ (1), \\ Enrique Rolando Pérez García ${ }^{8}$ (1), Luis Alberto Lazo Herrera ${ }^{9}$ (), Michael White ${ }^{10}$ (])
}

\author{
${ }^{1}$ Universidad Privada del Norte, PERU \\ ${ }^{2}$ Facultad de Estudios Superiores Iztacala, Universidad Nacional Autónoma de México, Tlanepantla de Baz, State of Mexico, MEXICO \\ ${ }^{3}$ Departamento de Psicología, Universidad Peruana Unión, Lima, PERU \\ ${ }^{4}$ Servicio de Cirugía Maxilofacial, Hospital General Universitario Carlos Manuel de Céspedes, Universidad de Ciencias Médicas de Granma, Bayamo, Granma, CUBA \\ ${ }^{5}$ Centro Provincial de Atención y Educación al Paciente Diabético, Hospital Provincial General Docente "Dr. Antonio Luaces Iraola”, Facultad de Ciencias Médicas "Dr. \\ José Asse Yara", Universidad de Ciencias Médicas de Ciego de Ávila, Ciego de Ávila, CUBA \\ ${ }^{6}$ Facultad de Ciencias Médicas "General Calixto García”, Universidad de Ciencias Médicas de La Habana, La Habana, CUBA \\ ${ }^{7}$ Facultad de Medicina No. 1 Universidad de Ciencias Médicas de Santiago de Cuba, Santiago de Cuba, CUBA \\ ${ }^{8}$ Policlínico Universitario Área Norte, Facultad de Ciencias Médicas "Dr. José Assef Yara", Universidad de Ciencias Médicas de Ciego de Ávila, Ciego de Ávila, CUBA \\ ${ }^{9}$ Facultad de Ciencias Médicas "Dr. Ernesto Che Guevara de la Serna”, Universidad de Ciencias Médicas de Pinar del Río, Pinar del Río, CUBA \\ ${ }^{10}$ Facultad de Ciencias Humanas y Educación, Universidad Peruana Unión, Lima, PERU \\ ${ }^{\star}$ Corresponding Author: tomas.caycho@upn.pe
}

Citation: Caycho-Rodríguez T, Valencia PD, Vilca LW, Corrales-Reyes IE, Hernández-García F, Pupo Pérez A, González Quintana P, Pérez García ER, Lazo Herrera LA, White M. Sociodemographic and Health Predictors of Concern about COVID-19 Infection in Cuban Patients with Type 2 Diabetes Mellitus. Electron J Gen Med. 2022;19(2):em360. https://doi.org/10.29333/ejgm/11620

\section{ARTICLE INFO}

Received: 25 Oct. 2021

Accepted: 20 Jan. 2022

\begin{abstract}
Introduction: Concern about becoming infected is a particularly relevant psychological aspect in the context of a pandemic, as it is associated with social reactions and behavioral changes.

Objectives: The present study sought to determine some sociodemographic and health factors associated with concern about COVID-19 infection in Cuban patients with type 2 diabetes mellitus.

Methods: 203 patients with type 2 diabetes mellitus, who attended nine primary care areas of four Cuban provinces belonging to different regions of the country (65.52\% female, mean age $57.5, S D=19.2)$, selected through non-probabilistic sampling, participated in the study. A sociodemographic questionnaire, the COVID-19 contagion concern scale (PRE-COVID-19) and an evaluation of blood glucose level were applied. Bivariate associations were examined with a series of analyses of variance (ANOVA). Adjusted (multiple) regression with all predictors running simultaneously was also used.
\end{abstract}

Results: Bivariate analyses showed that age, sex, education, occupation, having comorbidities, and having a family member or friend who had COVID-19 were significantly related to COVID-19 contagion concern. However, when all variables were included simultaneously, only age, technical education, having comorbidities, and having a friend or family member who had COVID-19 remained significant predictors of concern about COVID-19 infection.

Conclusions: Male patients, with a technical level of education, with comorbidities and those who had infected family members or friends presented greater concern for the contagion of COVID-19. The public health policies should develop strategies to assess the mental health of people belonging to vulnerable groups and provide interventions to promote mental health in those who show concern about infection.

Keywords: COVID-19, Cuba, diabetes mellitus, predictors, concern

\section{INTRODUCTION}

COVID-19 has affected more than 222 million people and has caused more than 4.5 million deaths worldwide [1]. Although most patients with COVID-19 develop mild symptoms or are asymptomatic, the effects can be much worse, especially in people with chronic diseases, such as patients with diabetes [2]. Diabetes mellitus (DM) is a leading cause of morbidity and mortality worldwide [3]. The estimated global prevalence of diabetes in 2019 was $9.3 \%$ (463 million people), which was estimated to increase to $10.2 \%$ (578 million) by 2030 and $10.9 \%$
(700 million) by 2045 [4]. In Latin America alone, in 2019, 31.6 million people were diagnosed with some type of diabetes; this figure could increase to 40.2 million by 2030 and 49.1 million by 2045 [4]. Among Latin American countries, Cuba has a prevalence of 66.9 patients with DM per 1000 population [5].

It has been estimated that the prevalence of DM in patients with COVID-19 varies around $0.15 \%$ to $28.98 \%$ [6]. Previous studies indicate that diabetes is an independent risk factor predicting severity of COVID-19, increased admissions to intensive care units and increased mortality in patients with COVID-19 $[7,8]$. It has been observed that $1.5 \%$ of in-hospital deaths related to COVID-19 occurred in patients with type $1 \mathrm{DM}$ 
and $31.4 \%$ in patients with type $2 \mathrm{DM}$; also, a mortality rate of 138 patients with type 1 DM per 100,000 people was observed [9]. Another study indicates that diabetic patients have almost four times the risk of severe disease and death from COVID-19 [10].

Additionally, people with diabetes present different psychosocial problems, which have been aggravated by the psychological stressors of the COVID-19 pandemic, social distancing and confinement [11]. During the current pandemic, it has been reported that $43 \%$ of diabetic patients had psychological distress, $75.8 \%$ had eating disorders, and $77.5 \%$ had moderate and/or severe sleep disorders [12]. Additionally, $28 \%$ of diabetic patients had generalized anxiety disorder [13], while, $34.1 \%$ and $27.3 \%$ reported stress and high anxiety respectively [14]. However, it has been estimated that approximately $45 \%$ of cases of mental health problems and psychological distress in people with diabetes go undetected [15]. Furthermore, people with diabetes are more concerned about becoming infected with COVID-19 than people without diabetes [16]. A study of people with diabetes in South and Central America indicated that the main fears of respondents were "being infected and not getting proper treatment" and/or "getting infected if you go to the hospital or doctor's appointments" [17]. Worry or concern is one of the most common and important psychological responses during the COVID-19 pandemic and is associated with the practice of protective behaviors against the disease $[18,19]$. In this sense, a higher level of concern is associated with a higher perceived threat of COVID-19 and a greater engagement in performing self-protective behaviors [20].

The above information suggests that a proper understanding of the factors associated with the mental health of patients with diabetes in the midst of the COVID-19 pandemic is highly important. Previous studies have reported the presence of different sociodemographic and health variables associated with the mental health status of the general population during the pandemic [21,22]. In the case of patients with diabetes, sociodemographic variables such as being female, a student, a single person, and reporting low income have been associated with a higher likelihood of reporting mental health problems [23]. It has been suggested that, in patients with diabetes, women were approximately 2 times more fearful of COVID-19 compared to men [24]. Regarding age, some suggest that it has no significant association with fear of COVID-19 in patients with diabetes [24]. However, others point out that older people, compared to younger people, have a statistically significant decrease in quality of life [25]. In relation to worry, women reported being more concerned about being severely affected by COVID-19 due to diabetes [26]. Also, people with medical complications associated with diabetes had a greater concern about being affected by COVID-19 compared to people without such complications [26].

Despite the above information, the association of different factors, such as age, gender, and DM-associated illnesses with the presence of significant levels of mental health concerns, including concern about COVID-19 transmission, has not been uniformly addressed. While it has been noted that there are no unified theoretical models that explain emotional reactions during pandemics [27], COVID-19 may affect individuals differently based on some sociodemographic and health factors. In this sense, the present study aimed to determine the sociodemographic and health factors associated with concern about COVID-19 infection in Cuban patients with DM. It is important to know and understand the factors associated with concern related to the disease, specifically, the concern for COVID-19 contagion, since this can serve as a basis for the formulation of public health policies that implement intervention strategies in health emergency situations, such as the current pandemic.

\section{METHODS}

\section{Participants}

A total of 203 patients with type 2 diabetes mellitus who attended nine primary care areas in four Cuban provinces belonging to different regions of the country (Pinar del Río, La Habana, Ciego de Ávila and Santiago de Cuba) participated in the study. Participants were selected by non-probabilistic sampling based on the following inclusion criteria:

1. have a diagnosis of type $2 \mathrm{DM}$ according to the World Health Organization criteria,

2. be older than 18 years old,

3. be patients of the health care areas mentioned above, and

4. be willing to participate in the study and to sign the informed consent form.

Patients with mental illness, cognitive deficit (dementia, psychosis or mental disability) or other apparent condition that prevents understanding and completion of the questionnaire were excluded. Although retrospective data on infection rates in diabetic patients suggest that people with type $1 \mathrm{DM}$ are at higher risk for infectious diseases in general, and death rates are similar to those of people with type 2 DM [28], this study focused on the latter for two main reasons. First, patients with type $1 \mathrm{DM}$ are mostly children and young people and the prevalence of this type of diabetes is lower compared to type 2 DM [29], which leads to a lower number of patients seen in consultation and primary health care. Second, the study was conducted in the context of the COVID-19 pandemic and patients with type 2 DM were the most accessible population to be surveyed by the research team in primary care areas.

The minimum sample size was calculated with the Soper software package [30] for a multiple regression study, according to the desired probability level $(\alpha=0.05)$, the number of predictors in the model (18 predictors), the anticipated effect size $\left(f^{2}=0.15\right)$ and the desired statistical power level (1$\beta=0.80$ ). The software suggested a minimum number of 118 participants; however, the final number was higher than the minimum required.

\section{Instruments}

\section{Socio-demographic and health information}

A questionnaire was developed specifically for this study, where participants were asked to provide information about their sex, age, educational level, type of work, cohabitation, marital status, presence of chronic complications, presence of comorbidities, family or friends infected with COVID-19, and time since diagnosis with DM. 


\section{Concern about COVID-19 contagion}

We used the COVID-19 contagion concern scale (PRECOVID-19) originally developed for the general population [31], which assesses worry about becoming infected with COVID-19 and its impact on people's mood and ability to perform daily activities. In this study we used the version validated for Cuban patients with diabetes [32], which consists of 5 items. All items have 4 Likert-type response options, ranging from 1=never or rarely to $4=$ almost all the time. The PRE-COVID-19 has a unidimensional structure, where the total score is calculated by adding the scores of each of the 5 items. Higher scores indicate greater concern about becoming infected with COVID19. The reliability of the PRE-COVID-19 for this study was very $\operatorname{good}(\omega=0.91)$.

\section{Blood glucose level}

Fasting blood glucose values were obtained from the patients' clinical histories and from blood tests performed in the last three months in laboratories equipped for this purpose. Based on this, poor glycemic control was determined as fasting blood glucose greater than or equal to $7 \mathrm{mmol} / \mathrm{L}$ (126 $\mathrm{mg} / \mathrm{dl}$ ) in the last three months and good control as figures below this value.

The criterion based on glycosylated hemoglobin ( $\mathrm{HbA1c})$ could not be used because it is not a test regularly available in the primary health care system where the survey was applied. Other control criteria using continuous glucose monitoring systems were not possible either, as they are not generally available for patients with DM living in Cuba.

\section{Procedure}

The questionnaire was applied by properly trained researchers, who complied with strict COVID-19 prevention health protocols, between the months of January and April 2021. The questionnaire was administered during patients' visits to primary care centers or in their homes. During this period of time, the fight against COVID-19 in Cuba suffered some setbacks, characterized by an increase in the number of infected people, even higher than that observed during the first stage of the disease, in 2020. Thus, during those dates, more than 64,414 positive diagnoses and 384 deaths were reported in the country.

Participation was voluntary and without any financial compensation. Participants signed the informed consent form and were informed that they could withdraw from the study at any time. Similarly, the reliability of the data was guaranteed. The study protocol was approved by the Ethics Committee of the Universidad Privada del Norte in Peru (registration number: 20213002).

\section{Data Analysis}

The frequencies and percentages of the categorical variables included in the model were examined. In the case of the outcome variable (concern about COVID-19 contagion), the mean \pm standard deviation (SD) was calculated for the total sample. These values were then also calculated for each category of each variable. For inferential purposes, bivariate associations were examined with a series of analyses of variance (ANOVA). The assumption of homoscedasticity was reasonably well met in most cases; however, a possible noncompliance with the assumption of normality of the residuals was observed. Therefore, we repeated the analyses after a power transformation of the outcome variable. Since the results were practically identical with both procedures, only those obtained with the variable in its original form are reported.

Variables that reached statistical significance $(p<.05)$ in the ANOVAs were selected as potential predictors in a linear regression. Crude (simple) regressions were run, which replicated the ANOVAs but also allowed for a more detailed examination of between-group differences. Finally, a fitted (multiple) regression was run with all predictors simultaneously. Statistical significance was judged from the 95\% Cls, which provide a set of possible values of the coefficient in the population. $\mathrm{A} \mathrm{Cl}$ that does not include zero is equivalent to a $\mathrm{p}<.05$ [33].

\section{RESULTS}

Table 1 presents the general information of the study sample. As can be seen, the sample was mostly female (65.52\%); in addition, the highest percentage was over 70 years old $(30.05 \%)$ followed by people between 40 and 59 years old (28.57\%). Also, a considerable number of people had higher education $(34.98 \%)$ and were retired at the time of data collection (35.47\%). Regarding the variables related with DM, it was observed that the majority had been diagnosed with DM for 5 or more years, as well as fasting glycemia levels $\geq 7 \mathrm{mmol} / \mathrm{L}$ (126 mmol/L) (52.71\%).

With respect to the bivariate analyses, it can be seen that age, sex, education level, occupation, having comorbidities, and having a family member or friend who had COVID-19 were significantly related to concern about COVID-19 contagion (Table 1). In detail, there appears to be a decrease in concern with increasing age, with a slight upward fluctuation from age 70 onwards. In addition, men, people with pre-university or technical education, patients with comorbidities and those who had infected family members showed greater concern; on the other hand, retired people seem to show less concern about infection (Table 2). On the other hand, when all variables were included simultaneously, only age, technical education, having comorbidities, and having a friend or family member who had COVID-19 remained significant predictors of contagion concern (Table 2).

\section{DISCUSSION}

People with DM are at increased risk of developing a severe case of COVID-19 [32] and suffer different psychosocial problems that are aggravated by pandemic stressors [34]. Concern about contagion is a particularly relevant psychological aspect in a pandemic context, as it is associated with social reactions and behavioral changes [35]. Therefore, the present study sought to determine some sociodemographic and health factors associated with worry about COVID-19 infection in Cuban patients with DM.

The results indicated that men were more concerned about the spread of COVID-19. This is at odds with some of the literature, where women with diabetes have higher levels of concern about contagion and general mental health problems $[24,26]$. A possible explanation for this result lies in the fact that men are at much higher risk of dying from COVID-19 than women, even after adjusting for differences in age or comorbidities [36]. 
Table 1. General information on the sample and association of the variables with concern about COVID-19 infection

\begin{tabular}{|c|c|c|c|c|c|c|c|}
\hline \multirow{2}{*}{ Variable } & \multirow{2}{*}{$n$} & \multirow{2}{*}{$\%$} & \multicolumn{5}{|c|}{ Concern about infection ( $M=2.79, S D=0.85)$} \\
\hline & & & M & SD & $\mathbf{F}$ & $\mathbf{p}$ & $\omega^{2}$ \\
\hline Age & & & & & 10.84 & $<.001$ & .13 \\
\hline$<40$ & 42 & 20.69 & 3.38 & 0.48 & & & \\
\hline $40-59$ & 58 & 28.57 & 2.79 & 0.84 & & & \\
\hline $60-69$ & 42 & 20.69 & 2.46 & 0.92 & & & \\
\hline$\geq 70$ & 61 & 30.05 & 2.63 & 0.83 & & & \\
\hline Sex & & & & & 4.72 & .031 & .02 \\
\hline Woman & 133 & 65.52 & 2.70 & 0.87 & & & \\
\hline Man & 70 & 34.48 & 2.97 & 0.80 & & & \\
\hline Education level & & & & & 8.01 & $<.001$ & .09 \\
\hline Secondary school or less & 35 & 17.24 & 2.57 & 0.76 & & & \\
\hline Pre-university & 60 & 29.56 & 2.93 & 0.93 & & & \\
\hline Technical/trade school & 37 & 18.23 & 3.27 & 0.61 & & & \\
\hline University & 71 & 34.98 & 2.54 & 0.82 & & & \\
\hline Occupation & & & & & 4.12 & .007 & .04 \\
\hline State worker & 67 & 33.00 & 2.95 & 0.80 & & & \\
\hline Self-employed & 37 & 18.23 & 3.03 & 0.80 & & & \\
\hline Unemployed/student/homemaker & 27 & 13.30 & 2.80 & 0.84 & & & \\
\hline Retired/pensioned & 72 & 35.47 & 2.53 & 0.88 & & & \\
\hline Lives alone & & & & & 1.18 & .279 & .00 \\
\hline No & 158 & 77.83 & 2.76 & 0.85 & & & \\
\hline Yes & 45 & 22.17 & 2.92 & 0.84 & & & \\
\hline Time since diagnosis with DM & & & & & 0.99 & .374 & .00 \\
\hline$<5$ years & 44 & 21.67 & 2.95 & 0.85 & & & \\
\hline 5 to 10 years & 61 & 30.05 & 2.78 & 0.84 & & & \\
\hline$>10$ years & 98 & 48.28 & 2.73 & 0.86 & & & \\
\hline Chronic complications & & & & & 2.83 & .094 & .00 \\
\hline No & 146 & 71.92 & 2.73 & 0.88 & & & \\
\hline Yes & 57 & 28.08 & 2.95 & 0.75 & & & \\
\hline Comorbidities & & & & & 23.91 & $<.001$ & .10 \\
\hline No & 132 & 65.02 & 2.59 & 0.83 & & & \\
\hline Yes & 71 & 34.98 & 3.17 & 0.76 & & & \\
\hline Fasting blood glucose & & & & & 0.53 & .466 & .00 \\
\hline Good control (<7 mmol/L) & 97 & 47.29 & 2.75 & 0.89 & & & \\
\hline Poor control ( $\geq 7 \mathrm{mmol} / \mathrm{L})$ & 107 & 52.71 & 2.84 & 0.82 & & & \\
\hline Friend or family member infected & & & & & 40.17 & $<.001$ & .16 \\
\hline No & 101 & 49.75 & 2.45 & 0.80 & & & \\
\hline Yes & 102 & 50.25 & 3.14 & 0.76 & & & \\
\hline
\end{tabular}

Table 2. Predictive model of COVID-19 infection concern

\begin{tabular}{|c|c|c|c|c|}
\hline \multirow{2}{*}{ Variable } & \multicolumn{2}{|c|}{ Raw regression } & \multicolumn{2}{|c|}{ Adjusted regression } \\
\hline & b & $95 \% \mathrm{Cl}$ & b & $95 \% \mathrm{Cl}$ \\
\hline \multicolumn{5}{|l|}{ Age } \\
\hline$<40$ & \multicolumn{2}{|c|}{ Reference group } & \multicolumn{2}{|c|}{ Reference group } \\
\hline $40-59$ & -0.59 & {$[-0.90,-0.27]$} & -0.40 & {$[-0.70,-0.11]$} \\
\hline $60-69$ & -0.91 & {$[-1.26,-0.57]$} & -0.46 & {$[-0.83,-0.10]$} \\
\hline$\geq 70$ & -0.75 & {$[-1.06,-0.44]$} & -0.25 & {$[-0.65,0.15]$} \\
\hline \multicolumn{5}{|l|}{ Sex } \\
\hline Woman & \multicolumn{2}{|c|}{ Reference group } & \multicolumn{2}{|c|}{ Reference group } \\
\hline Man & 0.27 & {$[0.02,0.52]$} & 0.14 & {$[-0.08,0.35]$} \\
\hline \multicolumn{5}{|l|}{ Education level } \\
\hline Secondary school or less & \multicolumn{2}{|c|}{ Reference group } & \multicolumn{2}{|c|}{ Reference group } \\
\hline Pre-university & 0.36 & {$[0.02,0.70]$} & 0.09 & {$[-0.23,0.40]$} \\
\hline Technical/Trade School & 0.70 & {$[0.32,1.08]$} & 0.38 & {$[0.02,0.74]$} \\
\hline University & -0.03 & {$[-0.36,0.30]$} & -0.13 & {$[-0.44,0.18]$} \\
\hline \multicolumn{5}{|l|}{ Occupation } \\
\hline State worker & \multicolumn{2}{|c|}{ Reference group } & \multicolumn{2}{|c|}{ Reference group } \\
\hline Self-employed & 0.08 & {$[-0.26,0.42]$} & 0.01 & {$[-0.28,0.30]$} \\
\hline Unemployed/student/homemaker & -0.15 & {$[-0.52,0.23]$} & -0.24 & {$[-0.59,0.11]$} \\
\hline Retired/pensioned & -0.42 & {$[-0.69,-0.14]$} & -0.21 & {$[-0.54,0.12]$} \\
\hline \multicolumn{5}{|l|}{ Comorbidities } \\
\hline No & \multicolumn{2}{|c|}{ Reference group } & \multicolumn{2}{|c|}{ Reference group } \\
\hline Yes & 0.58 & {$[0.35,0.82]$} & 0.32 & {$[0.09,0.54]$} \\
\hline \multicolumn{5}{|l|}{ Friend or family member infected } \\
\hline No & \multicolumn{2}{|c|}{ Reference group } & \multicolumn{2}{|c|}{ Reference group } \\
\hline Yes & 0.69 & {$[0.48,0.91]$} & 0.42 & {$[0.20,0.65]$} \\
\hline
\end{tabular}


Increased risk for a severe disease case would likely generate increased fear related to COVID-19 as a functional concern [37]. This is understandable, as people are concerned about their health and do not want to be infected with a virus that has a relatively high risk of death [38]. However, the vast majority of men in Latin American cultures like Cuba's have been socialized to cover up their fear, so it is important to understand how hiding fear affects men's response to COVID19. In this regard, it is also valuable to know whether the gender differences observed in this study are a product of concern about COVID-19 contagion, or are reflective of gender differences that arise independently of the problem.

Age is also a predictor of concern about contagion. In particular, a decrease in concern is observed with increasing age. This suggests that as people advance in age, they may be abler to cope with the uncertain situation posed by the COVID19 pandemic, unlike younger people who are worried about their future as well [39]. From the theory of socioemotional selectivity, differences in well-being according to age are generated by a change in the perspective of time throughout adulthood, where older people maximize positive experiences and avoid negative experiences [40]. In this sense, older people would be better able to regulate their emotions and cope with the stress of the pandemic [41].

Additionally, patients with diabetes and a technical level of education were significantly more concerned about the spread of COVID-19. Technical education in Cuba aims to provide initial and ongoing training for the skilled middle-level workforce, which will enable them to go on to university studies. Although, to our knowledge there are no similar findings in patients with diabetes or the general population, the literature suggests that people with better education are less concerned about COVID-19 infection [42]. This may reflect how different occupations are associated with different levels of prestige and access to resources or benefits that may be helpful in coping with stress or fear of COVID-19 and being less worried during a pandemic [43].

The presence of comorbidities in patients with DM also predicts a greater concern for contagion. The presence of comorbidities such as hypertension or cardiovascular disease in the majority of those people with diabetes who die from COVID-19 [44] may be associated with an increased risk of disease severity and fear [37]. The risk of health complications associated with diabetes may increase during a pandemic due to lower levels of control for the disease, which requires increased attention [45]. In addition, this risk may increase due to poor access to medications, syringes, medical consultations or laboratory results during a pandemic [17]. Thus, from a public health perspective, the identification and management of comorbidities and mental health problems among patients with diabetes should be a priority [46].

Finally, patients with DM who had family members or friends infected with COVID-19 presented greater concern about contagion. This is similar to what has been reported in other studies suggesting that people experienced greater fear and concern when contacting close people infected with COVID-19 [38,47]. Loss of contact with significant family and friends who have been infected with COVID-19 may decrease the perception of social support. This is important, as lack of social support from family or friends has been significantly associated with COVID-19-specific worry [42]. Diabetes has been referred to as a "family disease", affecting all family members [48]. Because the treatment of diabetes is complicated and complex, support from family and friends can help patients ease the burden of living with the disease [49], allowing them to gain self-confidence [50].

Despite the importance of thee findings, this study has some limitations: First, the non-probabilistic sample used does not allow us to generalize the results to all patients with DM attending primary health care systems in Cuba. Second, the data collection was conducted in a relatively short period of time, which prevented us from assessing the impact of predictors in different periods of the pandemic. Recent studies have shown that the psychological burden and fear of COVID19 varies between different periods of the pandemic [51]. This should lead to future studies which could evaluate the impact of the pandemic on mental health indicators of patients with diabetes at different stages of the pandemic. Third, the fact that the sample is mostly made up of women leads to a selection bias. This may lead to an underestimation of the contagion concern of male patients with DM. Fourth, the results are based on cross-sectional and not longitudinal data. Therefore, causality between variables cannot be assumed. Fifth, the study only included a limited set of possible sociodemographic and health predictors. Further research on concern about COVID-19 transmission and other associated factors, such as beliefs about COVID-19, intolerance to uncertainty, prevention behaviors, treatment adherence, etc., is suggested [52]. Sixth, the use of a self-report measure of contagion concern raises the possibility of social desirability bias.

Despite these limitations, the results of this study allow us to conclude that age, technical education, having comorbidities and having a friend or family member with COVID-19 remained significant predictors of concern about COVID-19. Specifically, that male patients with diabetes, with a technical school education, with comorbidities and those who had infected family members or friends were more concerned about the transmission of COVID-19. Thus, public health policies should foster the development of strategies to assess the mental health of people belonging to vulnerable groups, such as patients with diabetes, and provide timely interventions to promote mental health in those who show symptoms of concern about infection. Therefore, future studies to mitigate the negative psychological effects of the COVID-19 pandemic in patients with diabetes should consider these sociodemographic and health factors.

Author contributions: All authors have sufficiently contributed to the study, and agreed with the results and conclusions.

Funding: No funding source is reported for this study.

Declaration of interest: No conflict of interest is declared by authors.

\section{REFERENCES}

1. Coronavirus Resource Center. COVID-19 Dashboard by the Center for Systems Science and Engineering (CSSE) at Johns Hopkins University (JHU). 2021. Available at: https://coronavirus.jhu.edu/map.html

2. Pal R, Bhadada SK, Misra A. COVID-19 vaccination in patients with diabetes mellitus: Current concepts, uncertainties and challenges. Diabetes Metab Syndr. 2021;15(2):505-8. https://doi.org/10.1016/j.dsx.2021.02.026 PMid:33662837 PMCid:PMC7904463 
3. Palaiodimos L, Chamorro-Pareja N, Karamanis D, et al. Diabetes is associated with increased risk for in-hospital mortality in patients with COVID-19: A systematic review and meta-analysis comprising 18,506 patients. Hormones. 2021;20(2):305-14. https://doi.org/10.1007/s42000-02000246-2 PMid:33123973 PMCid:PMC7595056

4. Saeedi P, Petersohn I, Salpea P, et al. Global and regional diabetes prevalence estimates for 2019 and projections for 2030 and 2045: Results from the International Diabetes Federation Diabetes Atlas. Diabetes Res Clin Pract. 2019;157:107843. https://doi.org/10.1016/j.diabres.2019. 107843 PMid:31518657

5. Ministerio de Salud Pública. Dirección de Registros Médicos y Estadísticas de Salud. Anuario Estadístico de Salud 2020 [Ministry of Public Health. Directorate of Medical Records and Health Statistics. Health Statistics Yearbook 2020]. La Habana: MINSAP; 2021.

6. Nassar M, Nso N, Baraka B, et al. The association between COVID-19 and type 1 diabetes mellitus: A systematic review. Diabetes Metab Syndr. 2021;15(1):447-54. https://doi.org/ 10.1016/j.dsx.2021.02.009 PMid:33592371 PMCid: PMC7872855

7. Huang I, Lim MA, Pranata R. Diabetes mellitus is associated with increased mortality and severity of disease in COVID19 pneumonia-A systematic review, meta-analysis, and meta-regression. Diabetes Metab Syndr. 2020;14(4):395403. https://doi.org/10.1016/j.dsx.2020.04.018 PMid: 32334395 PMCid:PMC7162793

8. Liang $\mathrm{X}, \mathrm{Xu} \mathrm{J}$, Xiao W, Shi L, Yang $\mathrm{H}$. The association of diabetes with COVID-19 disease severity: Evidence from adjusted effect estimates. Hormones. 2021;20(2):409-14. https://doi.org/10.1007/s42000-020-00259-x PMid: 33236191 PMCid:PMC7685958

9. Barron E, Bakhai C, Kar P, et al. Associations of type 1 and type 2 diabetes with COVID-19-related mortality in England: A whole-population study. Lancet Diabetes Endocrinol. 2020;8(10):813-22. https://doi.org/10.1016/ S2213-8587(20)30272-2

10. Zheng Z, Peng F, Xu B, et al. Risk factors of critical \& mortal COVID-19 cases: A systematic literature review and metaanalysis. J Infect. 2020;81(2):e16-e25. https://doi.org/10. 1016/j.jinf.2020.04.021 PMid:32335169 PMCid:PMC7177098

11. Singhai K, Swami MK, Nebhinani N, Rastogi A, Jude E. Psychological adaptive difficulties and their management during COVID-19 pandemic in people with diabetes mellitus. Diabetes Metab Syndr. 2020;14(6):1603-05. https://doi.org/10.1016/j.dsx.2020.08.025 PMid:32862099 PMCid:PMC7443210

12. Alessi J, De Oliveira GB, Franco DW, et al. Mental health in the era of COVID-19: Prevalence of psychiatric disorders in a cohort of patients with type 1 and type 2 diabetes during the social distancing. Diabetol Metab Syndr. 2020;12(1):110. https://doi.org/10.1186/s13098-020-00584-6 PMid: 32879637 PMCid:PMC7457442

13. Khrwat A, Saadawi A. Generalized anxiety disorder among diabetic patients visiting gharyan-polyclinic in Libya during COVID-19 pandemic. BJPsych Open. 2021;7(S1):S265. https://doi.org/10.1192/bjo.2021.705

14. Ruissen MM, Regeer H, Landstra CP, et al. Increased stress, weight gain and less exercise in relation to glycemic control in people with type 1 and type 2 diabetes during the COVID19 pandemic. BMJ Open Diabetes Res Care. 2021;9(1):e002035. https://doi.org/10.1136/bmjdrc-2020002035 PMid:33431602 PMCid:PMC7802391
15. Mukhtar S, Mukhtar S. Letter to the editor: Mental health and psychological distress in people with diabetes during COVID-19. Metabolism. 2020;108:154248. https://doi.org/ 10.1016/j.metabol.2020.154248 PMid:32335075 PMCid: PMC7252044

16. Yan AF, Sun X, Zheng J, et al. Perceived risk, behavior changes and health-related outcomes during COVID-19 pandemic: Findings among adults with and without diabetes in China. Diabetes Res Clin Pract. 2020;167:108350. https://doi.org/10.1016/j.diabres.2020. 108350 PMid:32710996 PMCid:PMC7375325

17. Barone MTU, Villarroel D, de Luca PV, et al. COVID-19 impact on people with diabetes in South and Central America (SACA region). Diabetes Res Clin Pract. 2020;166:108301. https://doi.org/10.1016/j.diabres.2020.108301 PMid: 32623036 PMCid:PMC7332429

18. Prete G, Fontanesi L, Porcelli P, Tommasi L. The psychological impact of COVID-19 in Italy: Worry leads to protective behavior, but at the cost of anxiety. Front Psychol. 2020;11:566659. https://doi.org/10.3389/fpsyg. 2020.566659 PMid:33362631 PMCid:PMC7758243

19. Zysberg L, Zisberg A. Days of worry: Emotional intelligence and social support mediate worry in the COVID-19 pandemic. J Health Psychol. 2020;1-10. https://doi.org/10. 1177/1359105320949935 PMid:32811195

20. Vacondio M, Priolo G, Dickert S, Bonini N. Worry, perceived threat and media communication as predictors of selfprotective behaviors during the COVID-19 outbreak in Europe. Front Psychol. 2021;12:231. https://doi.org/10. 3389/fpsyg.2021.577992 PMid:33664691 PMCid: PMC7921485

21. Długosz P. Predictors of mental health after the first wave of the COVID-19 pandemic in Poland. Brain Sci. 2021;11(5):544. https://doi.org/10.3390/brainsci11050544 PMid:33925292 PMCid:PMC8145076

22. Paz C, Mascialino G, Adana-Díaz L, et al. Behavioral and sociodemographic predictors of anxiety and depression in patients under epidemiological surveillance for COVID-19 in Ecuador. PLoS One. 2020;15(9):e0240008. https://doi.org /10.1371/journal.pone.0240008 PMid:32997705 PMCid: PMC7526886

23. Al-Sofiani ME, Albunyan S, Alguwaihes AM, et al. Determinants of mental health outcomes among people with and without diabetes during the COVID-19 outbreak in the Arab Gulf Region. J Diabetes. 2021;13(4):339-52. https://doi.org/10.1111/1753-0407.13149 PMid:33351239

24. Basit KA, Zafar AB, Fawwad A, et al. The fear of COVID and depression in patients with diabetes at a tertiary diabetes care center in Karachi, Pakistan. Diabetes Metab Syndr. 2021;15(3):733-7.https://doi.org/10.1016/j.dsx.2021.03.008 PMid:33813249 PMCid:PMC7969844

25. Madsen KP, Willaing I, Rod NH, Varga TV, Joensen LE. Psychosocial health in people with diabetes during the first three months of the COVID-19 pandemic in Denmark. J Diabetes Complications. 2021;35(4):107858. https://doi.org /10.1016/j.jdiacomp.2021.107858 PMid:33573890 PMCid: PMC7816585

26. Joensen LE, Madsen KP, Holm L, et al. Diabetes and COVID19: Psychosocial consequences of the COVID-19 pandemic in people with diabetes in Denmark-what characterizes people with high levels of COVID-19-related worries? Diabet Med. 2020;37(7):1146-54. https://doi.org/10.1111/dme. 14319 PMid:32392380 PMCid:PMC7273071 
27. Taylor S. The psychology of pandemics: Preparing for the next global outbreak of infectious disease. Cambridge Scholars Publishing; 2019.

28. Peric S, Stulnig TM. Diabetes and COVID-19. Wien Klin Wochenschr. 2020;132(13):356-61. https://doi.org/10.1007/ s00508-020-01672-3 PMid:32435867 PMCid:PMC7238399

29. International Diabetes Federation. IDF Diabetes Atlas, 9th ed. Brussels, Belgium: International Diabetes Federation; 2019.

30. Soper DS. A-priori sample size calculator for structural equation models [Software]; 2021. Available at: https://www.danielsoper.com/statcalc/default.aspx

31. Caycho-Rodríguez T, Ventura-León J, Barboza-Palomino M. Diseño y validación de una escala para medir la preocupación por el contagio de la COVID-19 (PRE-COVID19) [Design and validation of a scale to measure concern about the spread of COVID-19 (PRE-COVID-19)]. Enferm Clin 2021;31(3):175-83. https://doi.org/10.1016/j.enfcli.2020.10. 034 PMid:33323307 PMCid:PMC7832364

32. Caycho-Rodríguez T, Vilca LW, Corrales-Reyes IE, et al. COVID-19 contagion concern scale (PRE-COVID-19): Validation in Cuban patients with type 2 diabetes. Diabetes Metab Syndr. 2021;15(5):102245. https://doi.org/10.1016/ j.dsx.2021.102245 PMid:34416467 PMCid:PMC8363424

33. Visintainer PF. Moving beyond significance testing: Confidence intervals in clinical research. J Thorac Cardiovasc Surg. 2021;161(4):1373-6. https://doi.org/10. 1016/j.jtcvs.2020.01.120 PMid:32482403

34. Saha S, Al-Rifai RH, Saha S. Diabetes prevalence and mortality in COVID-19 patients: A systematic review, metaanalysis, and meta-regression. J Diabetes Metab Disord. 2021;1-12. https://doi.org/10.1007/s40200-021-00779-2 PMid:33821206 PMCid:PMC8012080

35. Yang JZ, Chu HR. Who is afraid of the Ebola outbreak? The influence of discrete emotions on risk perception. J Risk Res. 2018;21(7):834-53. https://doi.org/10.1080/13669877. 2016.1247378

36. Dehingia N, Raj A. Sex differences in COVID-19 case fatality: Do we know enough? Lancet Glob Health. 2021;9(1):e14-5. https://doi.org/10.1016/S2214-109X(20)30464-2

37. Kohler H, Bäuerle A, Schweda A, et al. Increased COVID-19related fear and subjective risk perception regarding COVID-19 affects behavior in individuals with internal highrisk diseases. J Prim Care Community Health. 2021;12:2150132721996898. https://doi.org/10.1177/ 2150132721996898 PMid:33719697

38. Lin CY. Social reaction toward the 2019 novel coronavirus (COVID-19). Soc Health Behav. 2020;3(1):1-2. https://doi.org/10.4103/SHB.SHB_11_20

39. Blix I, Birkeland MS, Thoresen S. Worry and mental health in the COVID-19 pandemic: Vulnerability factors in the general Norwegian population. BMC Public Health. 2021;21(1):1-10. https://doi.org/10.1186/s12889-021-10927 -1 PMid:34001071 PMCid:PMC8127278

40. Carstensen LL, Fung HH, Charles ST. Socioemotional selectivity theory and the regulation of emotion in the second half of life. Motiv Emot. 2003;27(2):103-23. https://doi.org/10.1023/A:1024569803230
41. Wilson JM, Lee J, Shook NJ. COVID-19 worries and mental health: the moderating effect of age. Aging Ment Health. 2021;25(7):1289-96. https://doi.org/10.1080/13607863. 2020.1856778 PMid:33291948

42. Fegert JM, Vitiello B, Plener PL, Clemens V. Challenges and burden of the Coronavirus 2019 (COVID-19) pandemic for child and adolescent mental health: A narrative review to highlight clinical and research needs in the acute phase and the long return to normality. Child Adolesc Psychiatry Ment Health. 2020;14:1-11. https://doi.org/10.1186/s13034-02000329-3 PMid:32419840 PMCid:PMC7216870

43. Vallas SP, Finlay W, Wharton AS. The sociology of work: Structures and inequalities. New York: Oxford University Press; 2009.

44. Bingham M. In this issue of diabetes care. Diabetes Care. 2020;43:1369-70. https://doi.org/10.2337/dc20-ti07 PMid: 32561614

45. Sujan MS H, Tasnim R, Islam MS, et al. COVID-19-specific diabetes worries amongst diabetic patients: The role of social support and other co-variates. Prim Care Diabetes. 2021;15(5):778-85. https://doi.org/10.1016/j.pcd.2021.06. 009 PMid:34210639 PMCid:PMC8226038

46. Ducat L, Philipson LH, Anderson BJ. The mental health comorbidities of diabetes. JAMA. 2014;312(7):691-2. https://doi.org/10.1001/jama.2014.8040 PMid:25010529 PMCid:PMC4439400

47. Thombs BD, Bonardi O, Rice DB, et al. Curating evidence on mental health during COVID-19: A living systematic review. J Psychosom Res. 2020;133:110113. https://doi.org/10. 1016/j.jpsychores.2020.110113 PMid:32354463 PMCid: PMC7185913

48. Rad G S, Bakht LA, Feizi A, Mohebi S. Importance of social support in diabetes care. J Educ Health Promot. 2013;2:62. https://doi.org/10.4103/2277-9531.120864 PMid:24520558 PMCid:PMC3908488

49. Miller TA, DiMatteo MR. Importance of family/social support and impact on adherence to diabetic therapy. Diabetes Metab Syndr Obes. 2013;6:421-6. https://doi.org/ 10.2147/DMSO.S36368 PMid:24232691 PMCid:PMC3825688

50. Yazdanpanah F, Hamblin M R, Rezaei N. The immune system and COVID-19: Friend or foe? Life Sci. 2020;256:117900. https://doi.org/10.1016/j.lfs.2020.117900 PMid:32502542 PMCid:PMC7266583

51. Hetkamp M, Schweda A, Bäuerle A, et al. Sleep disturbances, fear, and generalized anxiety during the COVID-19 shut down phase in Germany: Relation to infection rates, deaths, and German stock index DAX. Sleep Med. 2020;75:350-3. https://doi.org/10.1177/ 2150132720953682 PMid:32865107 PMCid:PMC7457643

52. Al-Rahimi JS, Nass NM, Hassoubah SA, Wazqar DY, Alamoudi SA. Levels and predictors of fear and health anxiety during the current outbreak of COVID-19 in immunocompromised and chronic disease patients in Saudi Arabia: A cross-sectional correlational study. PLoS One. 2021;16(4):e0250554. https://doi.org/10.1371/journal. pone.0250554 PMid:33901260 PMCid:PMC8075243 